\title{
Book Review - 1
}

\section{Is transmission of knowledge more important than child-centeredness in early grades?}

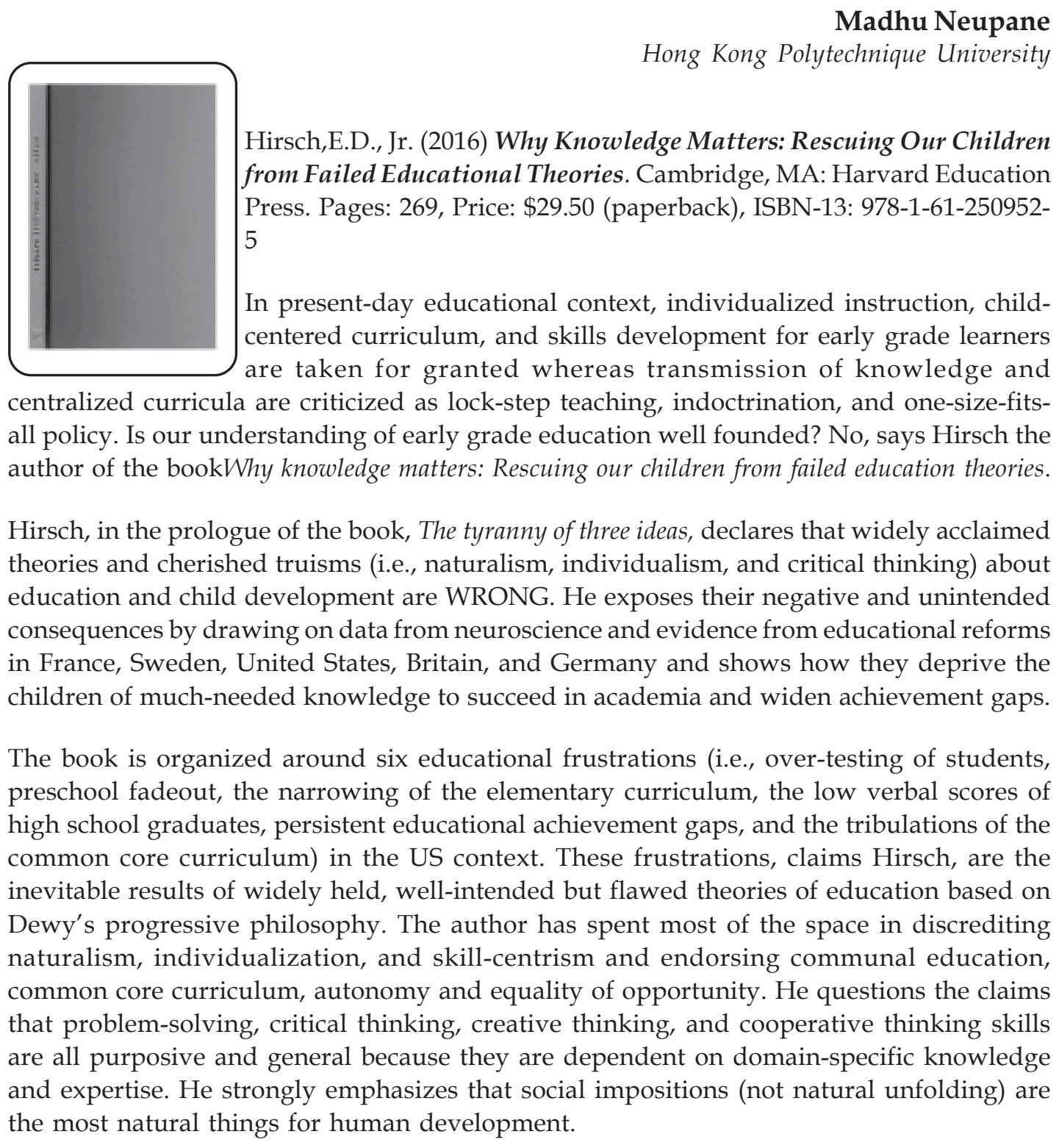

Journal of NELTA, Vol 23 No. 1-2, $\quad$ December 2018 
Hirsch claims that skills-based reading comprehension tests are invalid because they are not based on what is taught to students. Any test of reading, in his opinion, is about testing students' general knowledge and vocabulary. Therefore, a content-rich coherent curriculum rather than skill-focused approach would develop students' reading skills. He condemns the scapegoating of teachers as it blames them for the harms caused by flawed theories. He argues, "The real problem is idea quality, not teacher quality" (p. 37) and blames education schools for adopting underqualified students and offering programs heavy in pedagogy and light in content. His contention is that coherent knowledge-based curriculum is more important than effective teachers because a teacher can perform effectively in a coherent system. Hirsch believes that the lack of sustainability of gains made in preschool or elementary schools is the result of a fragmented curriculum and a knowledge-based curriculum would undoubtedly overcome this problem.

Hirsch draws on French educational reform to illustrate the detrimental effect of individualized content-diluted elementary curriculum, which has not only prevented learners from developing background knowledge and vocabulary required for reading but also widened achievement gaps between students belonging to different socio-economic strata. He argues that transmission of (shared public) knowledge is universal, natural, and essential for human development and equality of opportunity in a democracy. In contrast, hyper-individualism in language arts curriculum does more harm than good for children, places enormous pressure on teachers, deprives children of much-needed reading skills, and widens achievement gaps. Knowledge is crucial not only for developing children's reading skills but also for promoting their individuality. Therefore, according to Hirsch, language curriculum should be full of content like history, math, arts and science. He considers verbal skills of primary importance among twenty-first century skills. In this regard, reading ability "serves as a rough proxy for verbal expertise" (p. 85) and "Wellrounded education is the best means of attaining all-round reading skill" (p. 87). Hirsch underscores that almost everything is available in the Internet does not mean that almost everyone is ready to grab it. As money is required to earn money, knowledge is required to gain knowledge. The main reason for the persistence of achievement gap is the result of a fragmented curriculum, which makes poor children even poorer thereby widening the achievement gap. In Hirsch's view, the main aim of preschool education should be to enhance students' knowledge. In contrast, "Encouraging students to follow their interests leaves them with big holes in their knowledge and vocabulary" (p. 100).

Hirsch, in arguing that students' verbal abilities depend on their knowledge and vocabulary, finds skill-based reading instruction a delusion. Only through reading an adequate number of informational texts on a single domain for a sustained period can learners develop their reading skills. Discrediting naturalism in education, he argues that education "is a struggle against nature, to dominate it and produce the "up-to-date' person of the new era" (p. 124). To justify his argument, Hirsch highlights that harm done by individualized instruction in France should be a revelation about three disastrous pedagogical theories (i.e., naturalism, individualism, and skill-centrism) so that the infection does not spread further. Hirsch claims, "Individualism in the early grades disables many individuals" (p. 158) as is evident in the case of "United States, Britain, France, and Sweden" (p. 158).

$186 \quad$ Journal of NELTA, Vol 23 No. 1-2, $\quad$ December 2018 
The author enthusiastically promotes the knowledge-based schools. In his opinion, only such schools help students learn the language of power, feel empowered (as is the case in Japan and Finland), overcome inequality, gain further knowledge, and promote their language competence on an incremental basis. He repeatedly emphasizes that students need more knowledge than skills and claims that overemphasis on individuality in early year inhibits individuality because individuality comes from the mastery of shared conventions. He hopes that his book will play a role in intellectual liberation.

In the epilogue of the book, Breaking free, Hirsch admires Asian nations for being able to resist romantic philosophy of individualized instruction and doing well in education. He argues, the romantic philosophy of individualized instruction should be dethroned, the myth of imparting all-purpose skills should be broken, communal curriculum for each child should be ensured, and domain-restricted growth of expertise should be acknowledged for any meaningful educational reform to take hold. He highlights, "Only a well-rounded, knowledge-specific curriculum can impart needed knowledge to all children and overcome inequality of opportunity" (p. 191) and ends the book in optimistic note writing, "This will happen" (p. 191).

There is much to appreciate in Hirsch's book. Particularly worth considering for us, as language teachers are the importance of knowledge-based language curriculum, the significance of language competence to succeed, and centrality of reading for developing communication skills. As Hirsch claims, knowledge is important, a coherent curriculum is better than a fragmented one, certain knowledge is prerequisite for gaining further knowledge or even 'looking thing up' in the Internet, and reading is the best way to develop communication skills as well as vocabulary on gradual and incremental basis (Bruce, 2017; Derry, 2017; Joseph, 2017; Smith, 2018). Similarly, no one would dispute that teacher education should prepare teachers for the content they need to teach, the achievement gap in education should be minimized, and domain-specific expertise in knowledge is necessary for critical thinking and creativity.

However, one might dismiss some of the ideas advocated in the book. Hirsch goes too far in discrediting naturalism, individualism, and skills centrism in reducing them as a fragmented curriculum and creating dichotomies between naturaldevelopment over communal knowledge, individualization over a commoncurriculum, and skills over knowledge(Bruce, 2017). These aspects are complementary to each other rather than being mutually exclusive. Taking knowledge-based curriculum as a panacea for all educational ills from increasing students' educational achievement, maintaining cohesion in a society, to eradicating inequality is too simplistic. Hirsch also loses his balance in giving priority to knowledge over critical thinking and creativity as the scholars advocating critical thinking and creativity do not disregard the role of knowledge (Bruce, 2017). Besides, the author does not make it clear about the purpose of knowledge and role of an individual in its creation. Unlike Hirsch claims, child-centered education does not begin and end with children's interests but respects children's curiosity (Joseph, 2017). Furthermore, developing learners' reading skills involves much more than teaching a prescribed curriculum (Smith, 2018) because how learners grasp the concepts are of equal importance (Derry, 2017). 
In conclusion, the book is thought provoking and worth reading. It makes us see the other side of the coin and reexamine our widely held beliefs about education. Hirsch's plea for knowledge-based curriculum deserves respect and attention. However, we should not forget that knowledge-based curriculum could go along with child-centeredness and skill building. Knowledge mattersbut it is not the only thing that matters in education. Neither is a knowledgebased curriculum a panacea for all educational problems!

\section{References}

Bruce, B. C. (2017). Why knowledge matters: Rescuing our children from failed educational theories. Educational Theory, 67(5), 639-647. https://doi.org/10.1111/edth.12276

Derry, J. (2017). Why knowledge matters: Rescuing our children from failed educational theories. By E. D. Hirsch, Jr. British Journal of Educational Studies, 65(4), 517-519. https:/ /doi.org/10.1080/00071005.2017.1354531

Hirsch, E. D. (2016). Why knowledge matters: Rescuing our children from failed educational theories. Harvard Education Press.

Joseph, P. B. (2017). Why knowledge matters: Rescuing our children from failed educational theories. Educational Review, 69(4), 530-531. https://doi.org/10.1080/ 00131911.2017.1286818

Smith, J. K. (2018). Why knowledge matters: Rescuing our children from failed educational theories. The Journal of Educational Research, 0(0), 1-2. https://doi.org/10.1080/ 00220671.2018 .1443583 